\title{
The political economy of public transport pricing and supply decisions
}

\author{
Bruno De Borger and Stef Proost (*)
}

\begin{abstract}
This paper studies the political economy of public transport pricing and quality decisions in a hypothetical two-region federation. In each region there are two types of people: people not owning a car using only public transport, and car owners that demand both public transport and car trips. Each group may be a majority in the region and may also travel in the other region. Under regional decision-making, the political process may result in very low public transport fares, even if car owners are a large majority of the population. Cost recovery always improves with the share of outside users. Second, imposing a zero deficit constraint on regional public transport operators implements the second-best welfare optimum. Third, decentralized decision making leads to higher fares and better cost recovery. Our findings are consistent with very large public transport subsidies in Europe, and with the tendency towards decentralization of public transport policy-making.
\end{abstract}

JEL codes: H23, D62, R41, R48

Keywords: Public transport pricing, tax competition, federalism

(*) We are grateful to participants at the EIBurs seminar (Leuven, December 2013) and at the annual ITEA conference (Toulouse, June 2014) for helpful comments. We further thank Ruth Evers, two referees and André de Palma for many insightful remarks that substantially improved the final version of the paper. Financial support from FWO-Flanders and the EIBurs program is gratefully acknowledged. 


\section{Introduction}

Almost all public transport activities are heavily subsidized by the government: cost recovery rates of local public transport vary between as little as $10 \%$ and almost $100 \%$ (see, for example, Van Goeverden, Rietveld, Koelemeijer en Peeters (2006) and Savage (2010)) ${ }^{1}$. The subsidies come from the local, the regional or the federal government. It is rare to find local public transport systems that are almost fully funded by higher level governments, but especially when metro or light rail services are offered, important subsidies are provided (Reynolds-Fegan, Durkan and Durkan (2000)). This type of public transport is characterized by strong economics of density, and it can only be cost effective for big cities with high density (Tirachini, Hensher and Jara-Diaz (2010), Wang (2011)). Efficient pricing then requires a large subsidy also for operation costs (Parry and Small (2009)).

Who is in charge of public transport decision-making seems to widely differ across countries and, although there are exceptions, there has been a shift towards decentralized decision making in several countries ${ }^{2}$. For example, in the Netherlands, in the 1990's all investment in local public transport was funded by the central government. More recently, the pricing and operation of local public transport was decentralized to 19 regions that each received a lump-sum subsidy in function of their geographical characteristics. In the UK, all local public transport outside of London is privatized, and local governments can subsidize discounts for special categories of users. Sweden, Germany and France also have decentralized local public transport towards the regions in the last decennia. In Belgium, local public transport was first organized by each sub-region (province), but more recently decision making was centralized at the regional level (Flanders, Wallonia). The result in Flanders was a uniform service level and a uniform pricing system for all cities in the region, but individual cities could finance discounts and even offer free public transport for particular categories of citizens (retired people, students).

There is an extensive literature on the relative efficiency of different management structures for public transport operations. Surprisingly, although public transport absorbs an important part of the regional or city budget in many cities (in the Brussels Region, for example, this comes close to half of the budget), almost no literature exists on the political

\footnotetext{
${ }^{1}$ For detailed information on cost recovery rates, also see the database of the UITP.

${ }^{2}$ One may wonder whether tendencies towards decentralization are also observable in other sectors of the public domain. A general question in this respect is what determines the degree of decentralization in different sectors (health, education, transport, etc.) in different countries. A recent detailed study by the OECD (Blöchliger (2008)) shows a wide variety in decentralization across countries and across sectors. However, from the available information no clear picture emerges as to the determinants of decentralization.
} 
decisions determining the constraints for the management structure, such as the level of the fares, the level of subsidies and the minimum quality of service.

The purpose of this paper is to better understand the political economy of public transport pricing and quality decisions in urban areas. One intriguing question is why in many countries very large public transport subsidies seem to get fairly wide political support, even when car owners are by far the majority. It could be argued that this is due to distributive considerations: governments want low public transport fares to guarantee the mobility of low income people that cannot afford other means of transport. In this paper, we do not focus on such normative concerns but instead develop a political economy approach to public transport decisions; the political outcome depends on the size of the group of car owners versus people limited to public transport use, on the intensity of public transport use by both groups, and on pricing policies towards the use of cars. A second interesting puzzle is why so many countries opt for decentralization of local public transport (often combined with privatization). The literature has intensively studied the efficiency implications of privatization and contracting out but, surprisingly, the reasons for the increasing decentralization have received much less attention. Our political economy model provides a potential explanation.

We start from the framework developed for congestible local public goods (see De Borger and Proost (2013)). Their model predicts that, when the authority is given to the local government and users of the local public good have a majority, the user charge will be higher the more non-local users there are, and the higher the proportion of the population that is a user. More non-local users allow tax exporting, and a higher proportion of users implies that an individual voter receives a higher share of the revenues (or pays a smaller part of the deficit). The analysis also found that centralized provision may give rise to price and capacity discrimination between regions. Different institutional safeguards can be put in place to avoid this discrimination (for example, uniform prices). Finally, the analysis suggested that when only a minority of voters uses the local public good, the majority of non-users may well decide to have very high prices and low capacities.

Public transport has some peculiarities that require an adaptation of the model just discussed. First, public transport provision has increasing returns to scale, and both frequency and service quality are important characteristics of service supply. Second, there are few regions where people not owning a car (hence, they use only public transport) have a majority. Instead, in many regions car owners have a majority. Third, public transport subsidies can be a second-best response to too low prices for car use, once external costs of congestion and pollution are taken into account. 
We find some interesting results. Suppose regions decide on public transport policy fares and quality characteristics. We show that, if non car owners have the political majority in the region, fares will be below the marginal social cost if there are few outside users of the public transport system and there is no toll on road use. On the contrary, with many outside users and a road toll in place, the fare wanted by the median voter not owning a car may be much higher than the marginal social cost. We find that, if car owners are in charge at the regional political level, then the fare is increasing in the toll on car use and declining in road congestion; the fare also decreases if car owners get a larger share of the public transport users surplus. The implication is that the political process may result in low public transport fares and high subsidies, even if non car owners are a small minority of the population. Not surprisingly, cost recovery always improves with the share of users from outside the region. We further show that imposing a zero deficit restriction on public transport operations implements the second-best welfare optimum, independent of who is in charge at the regional political level. Comparing decentralized outcomes with policy decisions under centralized decision-making, it is found that under plausible conditions higher fares and improved cost recovery rates will result under decentralized decisions. Overall, our findings are consistent with the lack of opposition to very large public transport subsidies in Europe, and they provide a potential explanation for the tendency towards decentralization of public transport policy making observed over the last decades.

In section 2 we discuss briefly the literature and some empirical evidence. In section 3 we present the analytical model. The socially optimal fare, frequency and quality of public transport provision are derived in section 4, considering both the case with and without budgetary restrictions, and emphasizing the relation with un-priced external costs on the market for car use. In section 5 we analyze the outcome we can expect from political decisions by individual regions. Section 6 discusses public transport decisions by a federal government and presents a brief comparison between centralized and decentralized decisions. Finally, section 7 concludes.

\section{Literature review}

There is a large literature on the economics of public transport. At least three types of studies can be distinguished. First, pricing and service provision of public transport have been analyzed in detail from a normative, welfare economic viewpoint. Second, a large literature has developed on the role of the organizational form and the relative efficiency of private 
versus public operators. Third, a few papers have studied the political economy underlying public transport decisions. Although our paper clearly fits into this third category, we briefly review some relevant contributions to the different strands of literature.

Starting with the seminal paper by Mohring (1972), a first strand of literature has generated a large number of studies analyzing optimal pricing and service provision of public transport modes. Among many others, extensions of the basic model have focused on issues such as optimal bus size (Jansson (1980)), the impact of different subsidy formulas (Frankena (1983)), the role of discomfort externalities (Kraus (1991)), the impact of different operator objectives (Tirachini et al. (2010)), etc. Useful surveys are provided in Jara-Diaz and Gschwender (2003) and, more recently, Small and Verhoef (2007). Not surprisingly, a series of numerical models have also been developed to evaluate whether current public transport fares and service levels are above or below socially optimal levels. In several cases, it has been found that optimal fares may well be lower than current fares and, hence, larger subsidies may be justified. For example, both De Borger and Wouters (1998) and Proost and Van Dender (2008) found low optimal fares and high subsidies for Belgium and the city of Brussels, respectively. Similarly, Parry and Small (2009) show that in 2001 the optimal second-best subsidy for most forms of public transport in large agglomerations like London was higher than the subsidy actually observed. ${ }^{3}$ However, Kilani, Proost and Van der Loo (2014) studied a joint pricing reform of car and public transport use in Paris, taking into account that both the road and public transport networks are highly congested. Contrary to earlier studies, they found that even at current (too low) road charges, it is best to increase prices of public transport on some links. Moreover, fares should be increased in general whenever road pricing is put in place.

Another topic that has received much (mainly empirical) attention concerns the determinants of the performance of public transport operators in terms of technical and allocative efficiency, technical progress, etc. The recent focus has mainly been on the impact of different organizational forms, with detailed studies of the relative efficiency of private versus public provision of public transport services, the effect of competition between different suppliers of bus services for performance, and the implications of different types of contracts (see, e.g., Van de Velde (2007), Roy and Yvrande-Billon (2007), and Gagnepain, Ivaldi and Martimort (2013)). For surveys of this literature for the bus industry, see De Borger

\footnotetext{
${ }^{3}$ In their study, the main justification for the very high optimal subsidy (amounting to $90 \%$ of operating costs) was the important un-priced road congestion externality, combined with the strong assumption that for every two attracted public transport users, one would be a former car driver. For London, the situation before the congestion toll was taken as reference.
} 
and Kerstens (2008) and Gagnepain, Ivaldi and Vibes (2011)). However, the focus on efficiency measurement and the role of the type of contract may make us forget that the total budget and the major supply characteristics of public transport firms are in most countries still decided by the political level. These decisions are the topic of the current paper.

The scarce literature dealing with the political decisions that drive public transport pricing and supply is easily summarized. First, Brueckner and Selod (2006) develop a political economy model with endogenous location of households in which the type of transport system is endogenous. Cities can opt for different systems offering a different money cost/time cost combination. It is shown that in a city inhabited by voters with homogeneous skill levels -- and, hence, earning uniform incomes --, voters will make the socially optimal system choice, whatever the land ownership and associated rent effects of better urban transport systems. In a heterogeneous city, however, results are less clear. Under simple majority voting there could be a bias against capital-intensive, fast systems, resulting in a preference for bus systems rather than fast expressways. The main mechanism driving this bias is that highly skilled (high income) people live in the suburbs and vote for a fast system, but the median voter has not the same preference for speed. Second, a few papers explicitly analyze the political support for public transport subsidies or investment in infrastructure. For example, Borck and Wrede (2008) specifically focused on the determinants of political support for public transport subsidies in a model with two income groups and endogenous location. They show that rich automobile drivers may suffer from transit subsidies, whereas poor transit users may benefit from subsidies to automobiles. However, they do not study the mechanisms we analyze in this paper. Vandyck and Proost (2012) study a model with a central business district and neighboring regions. If wages in the central business district are endogenous, they show that neighboring regions that export labor may set too high transport fares and make too small public transport investments. Finally, the empirical analysis by Holian and Kahn (2013) studied political support for public transport investments. They used voting outcomes on a number of transit-related ballot propositions from state-wide elections in California for the period 1990-2010. Controlling for demographic, socio-economic and political ideological factors, their results suggest that suburbanization is a possible factor in determining public support for public transit investment. $^{4}$

\footnotetext{
${ }^{4}$ Glazer and Proost (2010) were interested in a slightly different question, viz. the provision of universal service (even in remote, low-demand areas) of, for example, public transport. They found that rent-seeking mechanisms at the federal level may explain too wide (in some cases universal) service provision.
} 


\section{Specification of the model}

In this section, we present the general structure of the model. After a brief overview of the general setting, we first discuss the specification of both the user cost and the operator cost of public transport in a given region. These specifications are based on an extensive literature (see, among many others, Mohring (1972), Jansson (1983), and Tirachini, Hensher and JaraDiaz (2010)); however, given our interest in strategic policy decisions rather than in the details of public transport supply and costs, we use simple specifications that capture the main drivers of public transport costs. Next we specify the cost of car use. Finally, we present the demand structure of the model. Note that we focus throughout on a single public transport line in each region.

\subsection{General setting}

We use a model with only 2 regions that have the same size; each region has $R$ voters. Within each region, we distinguish between two categories of voters. We assume some voters don't have a car ${ }^{5}$ and can only use public transport; the number of such voters is denoted as $U_{i}(i=1,2)$. Other voters are car owners, but given the availability of public transport services these people may also use public transport; their number is denoted as $C_{i}(i=1,2)$. Of course, we have $U_{i}+C_{i}=R(i=1,2)$. The proportion of both types of voters can differ between the two regions. The total number of voters in the federation composed of the two regions is, of course, $2 R$.

To describe the demand structure, let us start with the demand for public transport. There are three groups of public transport users in region 1 :

(i) The group of $U_{1}$ local inhabitants that can only use public transport; their demand in region 1 is denoted as $Y_{1}^{U}$.

(ii) The group of $C_{1}$ inhabitants of region 1 that demand both public transport and private car trips. Their public transport demand in region 1 is denoted $Y_{1}^{C}$.

(iii) People living in region 2 that also demand some public transport services in region 1. Public transport demand in region 1 by these outsiders is denoted

\footnotetext{
${ }^{5}$ Our model ignores the car ownership decision. We assume that individuals either have a car or not depending on income, garage availability, too old or too young for a drivers' licence, etc.
} 
$Y_{1}^{T}$. Note that public transport demand in region 1 by inhabitants from region 2 comes from the group $U_{2}$ that can only use public transport (demand $Y_{1}^{T^{U}}$ ) as well as from the $C_{2}$ car owners in region 2 that use both their car and public transport services (demand $Y_{1}^{T^{C}}$ ). This distinction is not important until section 6 below; there it plays an important role.

Denoting total public transport demand in region 1 by $Y_{1}$, we therefore have

$$
Y_{1}=Y_{1}^{U}+Y_{1}^{C}+Y_{1}^{T}, \text { where } Y_{1}^{T}=Y_{1}^{T^{U}}+Y_{1}^{T^{C}}
$$

Next consider the demand for car use in region 1. We take into account two groups of car users:

(i) The demand for car use in region 1 that comes from the group of $C_{1}$ inhabitants of this region that can use both car and public transport. Their demand for car use in the region is denoted $X_{1}^{C}$.

(ii) Furthermore, the group of $C_{2}$ inhabitants from region 2 makes car trips in region 1. This demand from outsiders is given as $X_{1}^{T}$.

As a consequence, total demand for car trips in region 1 is

$$
X_{1}=X_{1}^{C}+X_{1}^{T}
$$

The composition of demand for the two transport modes is summarized in Table 1 for region 1. Of course, similar definitions apply for region 2.

\begin{tabular}{|l|l|l|l|l|l|}
\hline & $\begin{array}{l}\text { Inhabitants of } \\
\text { region 1 using } \\
\text { public } \\
\text { transport only }\end{array}$ & $\begin{array}{l}\text { Inhabitants of } \\
\text { region 1 using } \\
\text { car and public } \\
\text { transport }\end{array}$ & $\begin{array}{l}\text { Inhabitants of } \\
\text { region 2 using } \\
\text { public } \\
\text { transport only }\end{array}$ & $\begin{array}{l}\text { Inhabitants of } \\
\text { region 2 using } \\
\text { car and public } \\
\text { transport }\end{array}$ & Total \\
\hline $\begin{array}{l}\text { Size of the } \\
\text { group }\end{array}$ & $U_{1}$ & $C_{1}$ & $C_{2}$ & $2 R$ \\
\hline $\begin{array}{l}\text { Public } \\
\text { transport use } \\
\text { in region 1 }\end{array}$ & $Y_{1}^{U}$ & $Y_{1}^{C}$ & $Y_{1}^{T^{U}}$ & $Y_{1}^{T^{C}}$ & $Y_{1}$ \\
\hline $\begin{array}{l}\text { Car use in } \\
\text { region 1 }\end{array}$ & 0 & $X_{1}^{C}$ & 0 & $X_{1}^{T}$ & $X_{1}$ \\
\hline
\end{tabular}

Table 1. Transport use in region 1 
Our formulation allows for a heterogeneous composition of each region (car owners versus non car owners) as well as for spillovers in the use of public transport and car use between regions. As our focus is on public transport decisions and to simplify the technical analysis without losing essential insights, we will impose additional structure on demand, see below. Moreover, a congestion toll or tax on car use may be in place; however, unless otherwise noted, this tax is assumed to be exogenously fixed. Of course, one could argue that private and public transport policies are jointly decided by the political process, but we prefer to look at public transport policies in isolation for two reasons. One is that in most countries the price per kilometer for car transport is guided by other considerations than public transport pricing and supply decisions; general transport tax policies (fuel taxes, road tolls, etc.) and public transport policies are often taken by different government agencies. The other is that the political economy of road tolls was studied in much detail in De Borger and Proost (2013)).

\subsection{The user cost of public transport}

The public transport literature referred to before (Jansson (1980), Tirachini et al. (2010), Jara-Diaz and Gschwender (2003)) argues that the user cost includes the fare, waiting time costs (at the bus or rail stop), access time costs (to go to bus or rail stop) and in-vehicle time costs. The latter include both the time cost when the vehicle is moving as well and the cost due to time losses at stops; the value of in-vehicle time depends on crowding. In general, one could specify the user cost as

$$
p+v_{w} \frac{1}{2 f}+v_{a} t_{a}+v_{i} t_{i}
$$

Here $p$ is the fare. The second term captures waiting time costs at the bus stop, assuming that users come to the stop ad random ${ }^{6} ; v_{w}$ is the value of waiting time at the stop, $f$ is the frequency offered. The third term are access costs. As our model does not have much spatial detail, we assume these costs to be constant and normalize them at zero. Finally, the last term captures in-vehicle time costs. In line with the literature we let the value of in-vehicle time $v_{i}$ depend on demand per vehicle, to reflect crowding. Moreover, it depends on investment in vehicle capacity or quality (vehicle size, seating capacity, etc.). In-vehicle time $t_{i}$ depends on

\footnotetext{
${ }^{6}$ Of course, strictly speaking this assumption is realistic only for transport services of sufficiently high frequency. De Borger and Fosgerau (2012) develop a model of public transport firms with passengers that can plan their trips or come to the stop ad random. The size of each group depends on the frequency of service offered and on the cost of planning trips; this in turn depends on the quality of information (about timetables, delays, etc.) provided by the firm.
} 
investment in speed-related characteristics (vehicle technology, on-board fare payment systems, etc.). Note that both investing more in vehicle capacity and in speed-raising technology reduces time costs. Capturing both types of investment in quality by $K$, we can summarize the in-vehicle time cost by a cost function

$$
C_{i}\left(\frac{Y}{f}, K\right)=\left(v_{i}\left(\frac{Y}{f}, K\right)\right)\left(t_{i}(K)\right)
$$

Here $Y$ is the total number of public transport trips demanded in the region, and $f$ is the frequency offered (per hour, per day, etc.).

Specifying $C_{i}($.$) linearly for simplicity, the total generalized user cost (1) per public$ transport trip, denoted $g^{Y}($.$) , becomes$

$$
g^{Y}(Y, p, f, K)=p+\alpha\left(\frac{1}{f}\right)+\beta_{0}+\beta \frac{Y}{f}-\gamma K
$$

Here $\alpha$ is (half) the value of waiting time, $\beta_{0}$ is the in-vehicle time cost at normal operating speed (it does not play much of a role in the model and will be normalized at zero in what follows), $\beta$ captures the crowding cost effect of higher demand per vehicle, and $\gamma$ captures the effect on user costs of investing in operating speed, quality, information, vehicle capacity, etc.. Note that access time costs are ignored. User cost formulation (2) is the reduced form specification that will be used in the rest of this paper.

\subsection{Operator costs of public transport supply}

Total operator costs per hour are the frequency times the costs associated with one driving cycle (doing the route once). The latter consist of cycle costs $C_{m}$ when the vehicle moves plus costs $C_{s}$ when the vehicle has to stop:

$$
T C=f *\left(C_{m}+C_{s}\right)
$$

The cycle costs when moving depend on investment in speed (the cycle time goes down) or in vehicle capacity (for example, a two-wagon tram has higher cycle costs than a large bus and than a small bus). Consistent with the literature, we assumed that the cycle cost per vehicle at stops depends on the number of passengers that have to board or leave per vehicle (see, e.g., Mohring (1972), Tirachini et al. (2010)). We can formulate these ideas by writing

$$
T C=f *\left(C_{m}+C_{s}\right)=f *\left[C_{m}(K)+C_{s}\left(\frac{Y}{f}\right)\right]
$$


Specifying the first cost function linearly $\left(C_{m}(K)=c_{0}+c_{K} K\right)$ and the second one linearly with constant marginal and average cost $\left(C_{s}\left(\frac{Y}{f}\right)=c_{Y} \frac{Y}{f}\right)$, we can write

$$
T C=f *\left[c_{0}+c_{K} K\right]+c_{Y} Y
$$

In this expression, $c_{Y}$ reflects the marginal cost of an extra passenger (loading, unloading) for the provider. Total costs of public transport further depend on the frequency $f$ offered and the quality of service $K{ }^{7}$ Interpretation of (3) is that a trip of minimum quality service costs $\mathrm{c}_{0}$ (we normalize the quality of such a service at $K=0$ for simplicity). If one wants quality above the minimum level (better seats, less noise, higher speed, etc,), this raises $K$ above the minimum level, increasing the cost per trip an arbitrary vehicle makes.

Our formulation (3) of the operator cost of public transport is consistent with Parry and Small (2009). It does not treat public transport as a public good, but it does allow for a strongly decreasing average operating cost per passenger, holding frequency and quality constant. Both the choice of $f$ and $Y$ (by setting $f$ and the fare) is left to the political decision maker. Note that specification (3) further implies that we neglect the fixed cost component of increasing quality by investing in fixed infrastructure such as bus or metro stations, administrative office buildings, etc. However, adding a fixed infrastructure cost to total cost does not alter our results as long as this fixed cost does not depend on quality or frequency. Although there may be exceptions, this is quite realistic in many cases; for example, the fixed cost of a bus station is unlikely to strongly depend on the quality of bus technology, or on the frequency of service offered.

Note again that (3) is a simplified reduced-form cost formulation. The implied separability and the assumption that fixed infrastructure costs are independent of frequency and quality simplifies the analysis of the political choices on the essential price and quality characteristics of public transport.

\subsection{The generalized cost of car use}

We assume the road network in a given region is congestible. Moreover, it is assumed that a toll per kilometer may be imposed on drivers, possibly to capture congestion externalities. Denoting the toll by $\tau^{\circ}$ and remembering that car transport demand was denoted

\footnotetext{
${ }^{7}$ Empirical evidence on public transport cost functions confirms the dependency of costs on the number of passengers as well as on operational characteristics such as frequency. For a discussion of relevant output indicators in public transport cost and performance modeling see, for example, the survey provided in De Borger and Kerstens (2008).
} 
by $X$, we specify the generalized cost of car transport $g^{X}\left(X, \tau^{\circ}\right)$ in the simplest possible way as follows (note that $v$, the slope of the congestion function, reflects the severity of extra traffic for congestion costs):

$$
g^{X}\left(X, \tau^{\circ}\right)=\tau^{\circ}+v X
$$

\subsection{Reduced-form demand for public transport and for car use}

In this section we describe the assumptions underlying the demand side of the model, and we derive reduced-form demands that relate demand for public transport and car use in a region as a function of all exogenous variables and parameters in the model.

Denote the generalized prices (including all user-relevant costs discussed above) of public transport and car use in a region by $P^{Y}, P^{X}$, respectively. The demand functions by the different groups $U, C$ and $T$ can then be specified in general as (taking into account that the group of local inhabitants $U$ only uses public transport):

$$
\begin{aligned}
& Y^{U}\left(P^{Y}\right), Y^{C}\left(P^{Y}, P^{X}\right), Y^{T}\left(P^{Y}, P^{X}\right) \\
& X^{C}\left(P^{Y}, P^{X}\right), X^{T}\left(P^{Y}, P^{X}\right)
\end{aligned}
$$

Total demands are obtained by aggregating demands of the relevant groups

$$
\begin{aligned}
& Y\left(P^{Y}, P^{X}\right)=Y^{U}\left(P^{Y}\right)+Y^{C}\left(P^{Y}, P^{X}\right)+Y^{T}\left(P^{Y}, P^{X}\right) \\
& X\left(P^{Y}, P^{X}\right)=X^{C}\left(P^{Y}, P^{X}\right)+X^{T}\left(P^{Y}, P^{X}\right)
\end{aligned}
$$

To simplify the exposition without affecting the qualitative results, we impose one additional assumption on the model. We will assume that for voters that use both their private car and public transport, the two modes are perfect substitutes. Although not crucial for the results, this drastically simplifies the derivations. Of course, it is a strong assumption, but it is not that unrealistic once one realizes that many non-monetary costs (waiting times at stops, access costs, congestion, etc.) have been included in the definition of the generalized costs.

The assumption of perfect substitutability allows us to invoke Wardrop's (1952) principle. In a user equilibrium the generalized costs of all alternatives between a given origin and destination will be equal, and these costs are less than those that would be experienced by a single user of an unused alternative. This has two implications. First, given an internal solution where both the private car and public transport are used by people of group $C$, in a user equilibrium there will be equality of the generalized prices of car and public transport trips. Second, corner solutions may occur under well-defined conditions. If the generalized cost of car use exceeds that of public transport when no person from group $C$ uses his car, then no person from $C$ will use the car option. Similarly, if the cost of public transport 
exceeds that of car use when no member of group $C$ uses public transport, then every member of this group will travel by car. We briefly return to the possibility of corner solutions below, but in what follows we initially focus on internal solutions.

Equality of equilibrium generalized prices allows us to write the demand system $X\left(P^{X}, P^{Y}\right), Y\left(P^{X}, P^{Y}\right)$ as $Y(P), X(P)$, where $P=P^{Y}=P^{X}$. In essence, a single price for a transport trip exists in equilibrium. Denoting $P(Y+X)$ as the inverse total transport demand function, we derive 'reduced-form' demand functions for car use and public transport by solving the following set of equilibrium conditions:

$$
\begin{aligned}
& P(Y+X)=p+\alpha \frac{1}{f}+\beta \frac{Y}{f}-\gamma K \\
& P(Y+X)=\tau^{\circ}+v X
\end{aligned}
$$

The expressions of the right-hand side are the generalized costs discussed before, see (2) and (4), respectively. The reduced-form demand functions that solve this system of two equations for $Y$ and $X$ yield demand for car and public transport use as a function of the public transport fare, frequency and quality, and of the road toll:

$$
\begin{aligned}
& Y^{r}\left(p, \tau^{\circ}, f, K\right) \\
& X^{r}\left(p, \tau^{\circ}, f, K\right)
\end{aligned}
$$

The equilibrium generalized price of a transport trip is then given as $P\left(Y^{r}()+.X^{r}().\right)$. The superscript ' $r$ ' refers to 'reduced-form' demands.

To determine the effect of an increase in the public transport fare on demand for public transport and car use, we totally differentiate (5) and use (2) and (4) to find:

$$
\begin{gathered}
\frac{d Y}{d p}=\frac{\partial Y^{r}}{\partial p}=\frac{\frac{\partial P(Y+X)}{\partial(Y+X)}-v}{\Delta}<0 \\
\frac{d X}{d p}=\frac{\partial X^{r}}{\partial p}=\frac{-\frac{\partial P(Y+X)}{\partial(Y+X)}}{\Delta}>0
\end{gathered}
$$

where

$$
\Delta=\frac{\beta}{f}\left(v-\frac{\partial P(Y+X)}{\partial(Y+X)}\right)-v \frac{\partial P(Y+X)}{\partial(Y+X)}>0 .
$$

As expected, a higher fare reduces public transport demand and raises car use.

Using similar derivations, we find the effect of frequency on demand: 


$$
\begin{aligned}
& \frac{d Y}{d f}=\frac{\partial Y^{r}}{\partial f}=\frac{\left[\frac{\partial P(Y+X)}{\partial(Y+X)}-v\right]\left[\frac{-(\alpha+\beta Y)}{f^{2}}\right]}{\Delta}>0 \\
& \frac{d X}{d f}=\frac{\partial X^{r}}{\partial f}=\frac{-\left[\frac{\partial P(Y+X)}{\partial(Y+X)}\right]\left[\frac{-(\alpha+\beta Y)}{f^{2}}\right]}{\Delta}<0
\end{aligned}
$$

Finally, better quality affects demand as follows:

$$
\begin{aligned}
& \frac{d Y}{d K}=\frac{\partial Y^{r}}{\partial K}=\frac{\left[\frac{\partial P(Y+X)}{\partial(Y+X)}-v\right](-\gamma)}{\Delta}>0 \\
& \frac{d X}{d K}=\frac{\partial X^{r}}{\partial K}=\frac{-\left[\frac{\partial P(Y+X)}{\partial(Y+X)}\right](-\gamma)}{\Delta}<0
\end{aligned}
$$

Frequency and quality of public transport raise public transport demand and reduce car use.

\section{The social optimum}

In this section, we briefly study the social optimum. As this will prove useful for later comparisons, we first consider the simplified case without any car use at all. Next, we introduce car use, accounting for road congestion and an exogenous road toll.

\subsection{The socially optimal solution: public transport only}

Given the absence of car traffic, the welfare maximization problem can simply be specified as the sum of net consumer surplus and fare revenues minus operating costs:

$$
\underset{p, f, K}{\operatorname{Max}}\left[\int_{0}^{Y} P^{Y}(y) d y-g^{Y}(.) Y\right]+p Y-f\left(c_{0}+c_{K} K\right)-c_{Y} Y
$$

Here $P^{Y}(y)$ denotes the inverse total demand function for public transport; the generalized user cost of public transport use $g^{Y}($.$) was defined by (2) above.$

In Appendix 1 we show that the socially optimal fare is given by

$$
p=c_{Y}+\frac{\beta}{f} Y
$$

The optimal fare is the marginal cost of an extra passenger plus the external cost of crowding: an extra passenger raises the generalized cost because of crowding, from which all users suffer. 
Next consider optimal frequency. We easily find (see Appendix 1) that it satisfies:

$$
\left(\frac{\alpha+\beta Y}{f^{2}}\right) Y=\left(c_{0}+c_{K} K\right)
$$

The left-hand side is the marginal benefit of a frequency increase (reduction in waiting time and crowding costs), the right hand side is the marginal cost of raising frequency for a vehicle of given quality $K$. Solving for frequency yields

$$
f=\sqrt{\frac{(\alpha+\beta Y) Y}{c_{0}+c_{K} K}}
$$

Frequency rises when crowding is more important and when the value of waiting time increases; moreover, it rises at higher demand. Frequency declines with higher costs of providing more frequent service or when offering higher quality. Of course, (12) is not a closed-form solution because demand itself depends on frequency, and the right hand side further depends on the fare and the quality offered. Also note that in the absence of crowding costs $(\beta=0)$ we get the standard square root formula often used in the early public transport literature, whereby optimal frequency rises in the square root of demand (see, for example, Mohring (1972) and Jansson (1980)).

Finally, optimal quality investment satisfies the condition (see Appendix 1)

$$
f c_{K}=\gamma Y
$$

As should be the case, the marginal cost of investment in quality equals the marginal benefit (the reduction in generalized cost for all users).

Expressions (11), (12) and (13) describe the social optimum. To find out whether this guarantees cost recovery, we use (11) and (12) in the definition of net revenues to find

$$
p Y-f\left(c_{0}+c_{K} K\right)-c_{Y} Y=\left(c_{Y}+\frac{\beta}{f} Y\right) Y-\left(\frac{\alpha+\beta Y}{f}\right) Y-c_{Y} Y .
$$

Working out and using (13) yields

$$
p Y-f\left(c_{0}+c_{K} K\right)-c_{Y} Y=-\frac{\alpha Y}{f}=-\frac{\alpha c_{K}}{\gamma}<0
$$

There is no full cost recovery. The loss of the public transport firm will be larger the larger the value of waiting time, the larger the marginal cost of investment $K$ in vehicle capacity and quality, and the smaller the beneficial effect of such investment on the generalized user cost. To understand the absence of full cost recovery, note that direct comparison with the well-known cost recovery theorems explored in the literature is not 
straightforward. They are derived in a setting where user costs depend on the transport volume and capacity of the system, and where capacity costs depend on the capacity level installed. In such a setting, exact cost recovery requires a user cost function that is homogeneous of degree zero in transport volume and capacity, and the capacity cost function must have constant returns to scale (see Mohring and Harwitz (1962), de Palma and Lindsey (2007) and De Borger, Dunkerley and Proost (2009) on cost recovery theorems). What (14) implies is that our model produces exact cost recovery only when the value of waiting time is zero. The reason is that in that case the user cost function is homogeneous of degree zero in demand and frequency, and the operator cost function has constant returns in frequency.

The implications of imposing full cost recovery are easily explored. Requiring $p Y-f\left(c_{0}+c_{K} K\right)-c_{Y} Y \geq 0$ yields, after simple algebra, the following optimal fare:

$$
p=c_{Y}+\frac{\beta}{f} Y-\frac{\lambda}{1+\lambda} \frac{Y}{\frac{\partial Y}{\partial P^{Y}}}
$$

where $\lambda$ is the multiplier associated with the constraint. For frequency and quality we find, using similar derivations as those described in Appendix 1, the rules (12)-(13).

Using these results and substituting the (binding) budget constraint we can eliminate $\lambda$ to find:

$$
p=c_{Y}+\frac{\beta}{f} Y+\frac{\alpha}{f}
$$

The fare is the same as in the social optimum only if the cost of waiting time $\alpha$ were zero. This is plausible, because in that case the optimal deficit equals zero, see (14) above.

\subsection{The social optimum with car use and un-priced car externalities}

One of the main economic justifications for subsidies to public transport is the secondbest argument that lower prices of transit indirectly address un-priced car congestion. In this subsection, we assume the generalized cost of road use to be linearly increasing in total road use in the region, as specified by $(4): g^{X}\left(\tau^{\circ}, X\right)=\tau^{\circ}+v X$. Assuming an exogenous road toll $\tau^{\circ}$ that is too low allows us to capture unpriced congestion ${ }^{8}$.

As argued before, the assumption of perfect substitutability between the two transport modes implies that in an internal equilibrium a single generalized price prevails for both car

\footnotetext{
${ }^{8}$ Other externalities of car use (wear and tear, air pollution) that affect all residents could be easily captured as well, as long as they are proportional to car use. This can be done by subtracting these other car externalities from the exogenous road toll $\tau^{\circ}$. Residents then receive less 'net revenues' from car use.
} 
and public transport use. It is easy to show that in that case we can formulate the problem of determining the second-best optimal public transport fare, frequency and quality as follows (assuming an interior solution so that both modes are used in equilibrium):

$\underset{p, f, K}{\operatorname{Max}} \int_{0}^{Y} P^{Y}(y) d y+\int_{0}^{X} P^{X}(x) d x-g^{Y}() Y-.g^{X}() X+.\left[p Y-f\left(c_{0}+c_{K} K\right)-c_{Y} Y+\tau^{\circ} X\right]$

In this expression, $P^{Y}(Y), P^{X}(X)$ are the inverse demands for public transport and car use. They are defined as the inverse demands associated with the demand functions $Y\left(P^{Y}, P^{X}\right), X\left(P^{Y}, P^{X}\right)$ previously defined, but imposing $P^{Y}=P^{X}$. Note further that $Y$ and $X$ depend on the policy variables $(p, f, K)$ through the reduced-form demands $Y=Y^{r}\left(p, \tau^{\circ}, f, K\right), X=X^{r}\left(p, \tau^{\circ}, f, K\right)$ identified above.

In Appendix 2 we show that the optimal fare rule can be written in the following form:

$$
p=c_{Y}+\frac{\beta}{f} Y+\left(\tau^{\circ}-v X\right) \Psi
$$

where

$$
\Psi=-\frac{\frac{d X}{d p}}{\frac{d Y}{d p}}=\frac{\frac{\partial P(Y+X)}{\partial(Y+X)}}{\frac{\partial P(Y+X)}{\partial(Y+X)}-v}>0 .
$$

This parameter reflects the degree to which an increase in the public transport fare induces users to switch from public transport to car use. It equals the increase in car use divided by the decline in transit use when the fare rises.

As expected, (16) implies that the optimal public transport fare is corrected downward when there is an un-priced externality on car use. The correction will be larger when a price decrease of the fare makes more car users switch to public transport. Observe that, when the exogenous toll equals marginal external congestion cost (hence, $\tau^{\circ}=v X$ ), then the fare boils down to $p=c_{Y}+\frac{\beta}{f} Y$. This is the optimal fare in the absence of car transport given before.

Straightforward algebra shows that the frequency and quality follow the same rules (12)-(13) we derived earlier (see Appendix 2 for details). Only the fare is used to correct the external cost of car use.

Finally, impose a no-loss restriction on public transport, and assume that the constraint is binding at the optimum. We can then write the optimal fare as (see Appendix 2): 


$$
p=c_{Y}+\frac{\beta}{f} Y+\frac{\lambda}{1+\lambda} Y v \Psi+\frac{1}{1+\lambda}\left(\tau^{\circ}-v X\right) \Psi
$$

Again, results for frequency and quality are the same as before. Interestingly, using the budget constraint we can eliminate $\lambda$ and substitute the result to find

$$
p=c_{Y}+\frac{\beta}{f} Y+\frac{\alpha}{f}
$$

This is the same as (15). The externality has disappeared from the price rule. In other words, the budget restriction on the public transport firm prevents the fare from correcting for the external cost of road use.

\section{The political economy of decentralized decisions}

In this section, we turn to the political decisions with respect to public transport if the regions autonomously decide on fares, frequencies and quality. It is assumed throughout that infrastructure and land use remain fixed. As mentioned before, we denote the number of voters that can only use public transport by $U$ and let the population be given by $R$. We assume regional political decisions are taken by simple majority voting. ${ }^{9}$ As we have only two homogeneous groups of voters, either car owners or people not owning a car will have the majority. In a simple voting game where a proposal is accepted when it can not be defeated by a majority, the group with the majority maximizes the utility of its representative member; this outcome is a voting equilibrium. We start by looking at the region's decisions if it controls all public transport policy instruments in an unregulated environment. Next we consider the region's behavior under a budgetary restriction.

\subsection{The unregulated regional political optimum}

Suppose first that those who can only use public transport (members of the group $U$ ) have a majority so that this group is decisive. We assume that preferences can be described by a quasi-linear utility function. Moreover, government surpluses or deficits are assumed to be

\footnotetext{
${ }^{9}$ In practice, transport, housing and labor markets are closely linked (due to, for example, the effect of transport policies on location decisions, the importance of commuting in total transport flows, etc.), and policy makers may not consider public transport policies in isolation. However, we follow much of the literature and isolate policies towards public transport conditional on household and firm location, and for given employment.
} 
equally shared among the whole population. Then a member of this group's decision is the solution of the following problem:

$$
\underset{p, f, K}{\operatorname{Max}} \frac{1}{U}\left[\int_{0}^{Y^{U}} P^{Y^{U}}(y) d y-g^{Y}(.) Y^{U}\right]+\frac{\left[p Y+\tau^{\circ} X-f\left(c_{0}+c_{K} K\right)-c_{Y} Y\right]}{R}
$$

In this expression, $P^{Y^{U}}\left(Y^{U}\right)$ is the inverse demand function for public transport use in the own region by people only using public transport. The first term in the objective function captures the user surplus for members of group $U$, expressed on a per person basis. The second term gives the net revenues of public transport operations plus the toll revenues on road use, expressed per person of the population. Observe that voters who only use public transport do not care about the reduction of road congestion, as they don't suffer from the time losses congestion implies for other road users. ${ }^{10}$

The first-order condition for the fare $p$ can be written as

$$
\frac{\theta^{U}}{U}\left[-Y \frac{d g^{Y}}{d p}\right]+\frac{1}{R}\left[\left(p-c_{Y}\right) \frac{d Y}{d p}+Y+\tau^{\circ} \frac{d X}{d p}\right]=0
$$

where we have introduced the notation $\theta^{U}$ for the share of demand by group $U$ in total public transport demand:

$$
\theta^{U}=\frac{Y^{U}}{Y}
$$

Of course, this share is endogenous, as both overall demand and demand by group $U$ depend on the fare and the quality characteristics. Similar algebraic steps as those extensively explained in Appendices 1 and 2 show that the rule describing the optimal fare is given by:

$$
p=\left(c_{Y}+\frac{\beta Y}{f}\right)+\left(1-\frac{\theta^{U}}{\eta}\right) Y v \Psi+\tau^{\circ} \Psi
$$

In this expression, we have defined

$$
\eta=\frac{U}{R} .
$$

\footnotetext{
${ }^{10}$ Of course, matters would be different if we added pollution or accident externalities to the model (see footnote 7 above). In that case public transport users would be negatively affected by emissions and by the accident risks due to car transport. Adding this complication would however not affect the main insights to be derived from the analysis below.
} 
This parameter captures the share of the population in the region that can only use public transport.

Expression (21) is the optimal fare rule if the majority of voters in the region are people that can only use public transport (hence $0.5<\eta \leq 1$ ) and decisions are taken by majority voting. The rule consists of three terms. The first term between brackets is the firstbest rule if road use was priced at marginal social cost. The second term is the 'bias' due to decentralized political decisions. If voters that can only use public transport do not have a large majority ( $\eta$ well below 1 ) but their share in total public transport use in the region is large ( $\theta^{U}$ is close to one), then public transport fares tend to be below marginal social cost. Fares wanted by the regional decision maker may in that case be very low, possibly zero. However, even though he himself is a public transport user, the same decision maker wants public transport to be much more expensive -- with fares above marginal social cost -- if the system is used to a large extent by people from outside the region and by local car owners (so that $\theta^{U}$ is close to zero). This is a direct application of a well-known general insight brought forward in a seminal paper by Arnott and Grieson (1981). Finally, the third term captures the idea that the public transport user wants higher fares if an increase in the public transport fare implies larger road toll revenues (distributed to all inhabitants): the higher fare induces people to switch from public transport to car, as captured by $\Psi$.

Comparing the political outcome (21) with the social optimum with unpriced car externalities as given by (16), we note two major differences. First, group $U$-- limited to using public transport -- ignores road congestion, unlike the social optimum. Second, the fare wanted by the group depends on their group size and on the importance of public transport use by car owners and by people from outside the region.

To conclude the discussion of public transport fare we point out that slightly rewriting (21) yields yet another insight. To see this, use (7), (8) and (17) to find

$$
\frac{Y}{\frac{\partial Y^{r}}{\partial p}}=\frac{\frac{\beta Y}{f}\left(v-\frac{\partial P(Y+X)}{\partial(Y+X)}\right)-v Y \frac{\partial P(Y+X)}{\partial(Y+X)}}{\frac{\partial P(Y+X)}{\partial(Y+X)}-v}=-\frac{\beta Y}{f}-v Y \Psi
$$

Using this result in (21) gives

$$
p=c_{Y}+\left(\frac{\theta^{U}}{\eta}\right) \frac{\beta Y}{f}-\left[1-\frac{\theta^{U}}{\eta}\right] \frac{Y}{\frac{\partial Y^{r}}{\partial p}}+\tau^{\circ} \Psi
$$


This alternative formulation shows that the voter who only uses public transport internalizes only part of the crowding externality (captured by $\frac{\beta Y}{f}$ ) in the fare. Specifically, he accounts for crowding only to the extent that it affects members of his group $\left(\theta^{U}\right)$ and in as far as he shares in the fare revenues $(1 / \eta)$.

Straightforward algebra further shows that the voter that can only use public transport will set frequency and quality of service investment according to the first-best rules (12)-(13) given before. Interestingly, political decisions on fares substantially deviate from the social optimum, but frequency and quality follow the socially optimal rules. Note that this finding is a consequence of our cost function specifications. Of course, as the fare may be too high or too low, the same holds for frequency and quality.

Will public transport costs be fully recovered? Using the optimal rules for the decision variables in the definition of net revenue, we easily show

$$
p Y-f\left(c_{0}+c_{K} K\right)-c_{Y} Y=-\frac{\alpha c_{K}}{\gamma}+\left(1-\frac{\theta^{U}}{\eta}\right) Y^{2} v \Psi+\tau^{\circ} \Psi Y
$$

In general, cost recovery can be positive (for example, if road tolls are high and the public transport system is mainly used by people from outside the region or by car owners, and waiting time costs are small) or negative (if mainly locals use the public transport system and no road toll is implemented). Note that these observations provide an empirically testable hypothesis: we expect cost recovery to be better when road charges are high and the public transport system is highly used by local car owners and by people from outside the region.

We summarize our findings in Proposition 1.

Proposition 1. Decisions on public transport fares, frequency and quality of service when voters that can only use public transport have a majority.

a. If there are few other users of the public transport system and there is no toll on road use, public transport fares are below the marginal social cost, because part of the costs are shifted to non-users and the benefits of reduced road congestion are not taken into account. 
b. Public transport fares may well be much higher than marginal social cost if public transport is widely used by car owners and people from outside the region, and if road use is tolled.

c. Depending on the share of users from outside the region, revenues may or may not be sufficient to cover the public transport operator's costs. Cost recovery always improves with the share of outside users.

Next, let us assume - which is probably more realistic in many regions -- that a voter who is a car owner is decisive in the region (hence, a member of group $C$ ). He considers the following problem:

$$
\begin{aligned}
\operatorname{Max}_{p, f} \frac{1}{R-U} & {\left[\int_{0}^{Y^{c}} P^{Y^{C}}\left(y^{C}\right) d y-g^{Y}(.) Y^{C}\right]+\frac{1}{R-U}\left[\int_{0}^{X^{c}} P^{X^{C}}(x) d x-g^{X}(.) X^{C}\right]+} \\
+ & \frac{1}{R}\left[p Y-f\left(c_{0}+c_{K} K\right)-c_{Y} Y+\tau^{\circ} X\right]
\end{aligned}
$$

A car owner's welfare consists of three components. The first component is, expressed per person, his direct net surplus from public transport use $\left(P^{Y^{C}}\left(Y^{C}\right)\right.$ is the inverse demand function for public transport by people from group $C$ ). The second term captures his indirect net user benefit from car use in his own region; this is also affected by changes in public transport fares, as the fare induces changes in the number of local car trips made. The final term is the voter's share in net revenues.

Solving the above problem using similar techniques as before, we find the fare preferred by voters who are car owners. Analogous to (21) and (23) given above, it can be written in two different forms as follows:

$$
\begin{aligned}
& p=\left(c_{Y}+\frac{\beta Y}{f}\right)+\left[1-\frac{\theta^{C}}{1-\eta}\right] Y v \Psi+\left(\tau^{\circ}-\frac{\rho^{C} v X}{1-\eta}\right) \Psi \\
& p=c_{Y}+\left[\frac{\theta^{C}}{1-\eta}\right] \frac{\beta Y}{f}-\left[1-\frac{\theta^{C}}{1-\eta}\right] \frac{Y}{\frac{\partial Y^{r}}{\partial p}}+\left(\tau^{\circ}-\frac{\rho^{C} v X}{1-\eta}\right) \Psi
\end{aligned}
$$

In these expressions, $\theta^{C}$ is the fraction of demand by group $C$ in total public transport demand in the region (as before, note that this fraction is endogenous and depends on the policy variables such as the fare):

$$
\theta^{C}=\frac{Y^{C}}{Y}
$$


The notation $\rho^{C}$ is in a similar way used to denote the fraction of car demand in the region that comes from this group of local car owners (the remainder comes from drivers from outside the region):

$$
\rho^{C}=\frac{X^{C}}{X}
$$

Finally, the share of the people living in the region that demand both car and public transport trips as fraction of the region's population is given by

$$
1-\eta=\frac{C}{R}
$$

Consider the interpretation of the result as given in (24). Note that the fare will be lower the larger the share of public transport demand by car owners and the lower the road toll. The fare declines in congestion and, assuming the toll is below the marginal external cost borne by car owners, it rises in the responsiveness of people to use their car more. Car owners prefer that public transport fares charge for crowding in public transport in as far as they use

public transport $\left(\theta^{C}\right)$ and in as far as they can share in the fare revenues $(1 / 1-\eta)$. Car owners who use both modes only pay attention to road congestion by lowering the fare to the extent that they suffer from it, as captured by the fraction $\rho^{C}$, and in as far as they do not have to pay the full cost of it (as captured by $(1-\eta)$ ).

Differentiating the objective function with respect to frequency and quality, using earlier expressions and the optimal fare rule, we again find the first-best rules for the two supply variables. Since we found the same result also when people only using public transport had a majority, the rules for quality and frequency are first-best, independent of who is in power. These findings follow from the characteristics of the user and operator cost functions of public transport. We summarize this finding in the following Lemma.

\section{Lemma 1: Under our assumptions, frequency and quality of service follow the first-best rules, independent of which group is decisive. Hence, conditional on the number of users, frequency and quality are first-best.}

Using the pricing, frequency and quality of service rules, we again see that cost recovery is not guaranteed. We find

$$
p Y-f\left(c_{0}+c_{K} K\right)-c_{Y} Y=-\frac{\alpha c_{K}}{\gamma}+v \Psi Y^{2}\left[1-\frac{\theta^{C}}{1-\eta}\right]+\left(\tau^{\circ}-\frac{\rho^{C} v X}{1-\eta}\right) \Psi Y
$$


Costs will not be fully recovered if waiting time and marginal capacity costs are large.

Finally, consider the possibility of corner solutions. In that case, generalized prices faced by car owners do not equalize in the Wardrop equilibrium, and either they use only their car $\left(\theta^{C}=0\right)$ or use only public transport $\left(\rho^{C}=0\right)$. If they do not use public transport at all, they only care about public transport to the extent that it yields revenues. On the contrary, if they only use public transport, they want fares to be low if there is little crowding on public transport and the road toll is low. However, high road tolls and crowding in public transport will induce them to want higher public transport fares.

We summarize our findings in the following proposition:

Proposition 2. Political decisions on public transport fares, frequency and quality of service when car owners have a majority.

a. The fare wanted by car owners is increasing in the toll on car use. It decreases if car owners have a larger share in total public transport use.

b. Depending on the share of users from outside the region, revenues may or may not be sufficient to cover the public transport operator's costs. Cost recovery always improves with the share of users from outside the region.

The policy implication from proposition 2 is clear. It implies that voters that use both transport modes may agree on setting low public transport fares and allowing large subsidies. They will do so if there is substantial congestion in the urban area and there is no road toll (or a toll that is too low compared to marginal external cost), a set of conditions that holds in many cities.

The comparison of the desired public transport policies by voters from groups $U$ and $C$ yields some interesting conclusions. To see this, consider expressions (23) and (25). There are two major differences between the policies wanted by voters that only use public transport and those also driving their car. One is that each group is concerned with their own share in the net consumer surplus of public transport use, so that they only care about crowding in public transport to the extent they are directly affected. The other difference is that the first group $U$ only cares about the toll revenues from road use, whereas group $C$ is also concerned about reducing the road congestion from which it suffers. This leads to the following insights. First, if relative to their voting majority the user shares of groups $U$ and $C$ are equal (in 
essence, if $\left.\frac{\theta^{U}}{\eta}=\frac{\theta^{C}}{1-\eta}\right)$, then car owners in fact may want a lower public transport fare than people always using public transport. To see this it suffices to look at the final terms on the right hand sides of (23 and (25). The reason is that car owners care about reducing congestion; this can be achieved by lower public transport fares. Second, assume more plausibly that $\frac{\theta^{U}}{\eta}>\frac{\theta^{C}}{1-\eta}$. The second terms on the right hand side of (23) and (25) suggest that this would reduce the fare wanted by non-car owners $U$ relative to those desired by car owners $C$. We summarize in the following Proposition.

Proposition 3. Comparing the political decisions of car owners and non-owners

a. Non car owners (group $U$ ) will opt for lower public transport fares than car owners (group C) if the share of non-car users in public transport use is large and there is little road congestion (or mainly outsiders suffer from congestion).

b. Car owners (group C) will want lower public transport fares than non-car owners (group $U$ ) if car owners suffer substantially from congestion and the exogenous road toll is low.

c. When in charge, both car owners and non-car owners may opt for low public transport fares.

\subsection{Regional decisions under a budgetary restriction on public transport}

We found that the political decisions at the regional level deviate from the social optimum. Moreover, cost recovery is not guaranteed, although under some specific conditions net revenue may be positive. In this section, we study the role of imposing a formal budget constraint on the political process.

If voters that only use public transport have a majority, the problem to be studied is

$$
\begin{gathered}
\operatorname{Max}_{p, f, K} \frac{1}{U}\left[\int_{0}^{Y^{U}} P^{Y^{U}}(y) d y-g^{Y}(.) Y^{U}\right]+\frac{\left[p Y-f\left(c_{0}+c_{K} K\right)-c_{Y} Y+\tau^{\circ} X\right]}{R} \\
\text { s.t. } \frac{\left[p Y-f\left(c_{0}+c_{K} K\right)-c_{Y} Y\right]}{R}=0
\end{gathered}
$$


Associating a multiplier $\lambda$ with the constraint, we find the following rule for the optimal fare (see Appendix 3):

$$
p=\left(c_{Y}+\frac{\beta Y}{f}\right)+\left(1-\frac{\theta^{U}}{\eta} \frac{1}{1+\lambda}\right) v Y \Psi+\tau^{\circ} \frac{1}{1+\lambda} \Psi
$$

It is easy to show that frequency and quality are again determined according to the rules given before. Using these results and substituting the budget restriction in (26) the latter can be rewritten, after rearrangement, as:

$$
p=\left(c_{Y}+\frac{\beta Y}{f}\right)+\frac{\alpha}{f}
$$

Note that the fare rule is identical to the rule in the second-best welfare optimum given before (see (15)). This implies that, if users have a majority, decentralized decision making under a zero profit constraint implements the second best welfare optimum.

If a car owner is decisive in the region, the problem is

$$
\begin{gathered}
\underset{p, f, K}{\operatorname{Max}} \frac{1}{R-U}\left[\int_{0}^{Y^{C}} P^{Y^{C}}(y) d y-g^{Y}(.) Y^{C}\right]+\frac{1}{R-U}\left[\int_{0}^{X^{c}} P^{X^{C}}(x) d x-g^{X}(.) X^{C}\right]+ \\
+\frac{1}{R}\left[p Y-f\left(c_{0}+c_{K} K\right)-c_{Y} Y+\tau^{\circ} X\right] \\
\text { s.t. } \quad \frac{1}{R}\left[p Y-f\left(c_{0}+c_{K} K\right)-c_{Y} Y\right]=0
\end{gathered}
$$

Solving the above problem, we find the fare preferred by voters who also rely on car driving:

$$
p=c_{Y}+\frac{\beta Y}{f}+\left[1-\frac{\theta^{C}}{1-\eta} \frac{1}{1+\lambda}\right] v Y \Psi+\left(\tau^{\circ}-\frac{\rho^{C} v X}{1-\eta}\right) \frac{1}{1+\lambda} \Psi
$$

As several times before, the rules for frequency and quality are the first best rules derived before. Substituting the budget restriction for the public transport operator, we again find the second-best optimal fare (15). Combining this and our earlier finding of this subsection yields the following Lemma.

\section{Lemma 2: The (second-best) budget constrained welfare optimum can be implemented} by decentralized decision making, independent of who is in charge at the political level.

Of course, this result hinges upon two important assumptions of our analysis. First, we implicitly assumed that no price-discrimination is allowed, otherwise non-locals would always be discriminated against and we lose the second-best property. The no price- 
discrimination rule forces local governments to do as well as possible for their local voter, so they are forced to also optimize the conditions for non-local users. Second, the fact that frequency and quality are socially optimal (conditional on demand) depends on the characteristics of the user and operator cost functions we assumed. Conditional on the frequency and quality rules we found, the budget constraint then forces the fare to be set at the second-best welfare optimum. Allowing more complex interactions in the cost functions would destroy the optimality of quality and frequency, and the result may no longer hold.

\section{Centralized decisions}

One may wonder whether it is a good idea to let cities, urban areas or regions within a country decide on public transport fares and quality attributes of the regional public transport system. In fact, there are good reasons to believe that this will indeed be the case. For example, regional decisions may better reflect local demand and congestion conditions than when a central government agency determines fares, frequencies and quality aspects of public transport operations for the different regions or urban areas. Of course, a disadvantage of decentralized decisions is that regions may engage in tax exporting behavior (see Arnott and Grieson (1981)). Hence, it is a priori unclear which political system performs best.

As noted in the introduction, in many countries a tendency has been observed over the past decades towards decentralized decision making for public transport services. To understand this tendency, we study in this section what the outcomes of centralized decision making would be in our simplified setting, and we compare with our findings under decentralization (see Section 5).

A complete analysis of centralized decision making requires looking at many different cases depending on which type of voter has a majority in each of the regions (car owners may have a majority in both regions, non-car owners may have a majority in both regions, or in one region there may be a car owner majority whereas this is not the case in the other region). Moreover, different political mechanisms to reach decisions exist at the central level. Two popular models assume that either a minimum winning coalition decides at the central level, or that decisions are the result of a bargaining process (Lockwood (2002), Besley and Coate (2003), Hickey (2013)). In our two-region model, one way to model decisions by a minimum winning coalition is to assume that regions each delegate one representative to the central level to form a central parliament, and that each representative has an equal probability of being decisive at the central level. Bargaining would imply that elected regional representatives negotiate in a central parliament to reach decisions. Finally, the central level 
may further operate under various constitutional constraints, including a uniform policy requirement across regions, or it may be subject to regional or global budgetary constraints.

It is impossible to work out centralized decisions for all possible cases that can be imagined. In this section, we focus on a specific but especially relevant case where car owners have the majority, the two regions are symmetric and only uniform prices are allowed. First, the case where car owners have a majority in both regions seems quite realistic for many countries. Moreover, the qualitative results when people that only use public transport are in charge (and both regions are symmetric) can be directly derived from the model analyzed in De Borger and Proost (2013): although they focused on road users and road pricing decisions, their findings can with minor adaptation be reinterpreted for public transport ${ }^{11}$. Second, we focus on the symmetric case ${ }^{12}$ : we assume all parameters are identical in the two regions. The advantage of doing this is not only that the asymmetric case yields results that are difficult to interpret (unlike the symmetric case), but also that under symmetry we can show (see Appendix 4) that the fare and quality rules for decision making by a minimum winning coalition and decisions obtained through bargaining are the same. Third, we assume that decision makers at the central level have to respect a uniformity constraint: fares have to be the same in both regions. Based on the comparison of centralized versus decentralized decisions in a different context, we expect centralized decisions without such constraints to produce inferior results as compared to decentralization (De Borger and Proost (2013)). It is mainly the potential exploitation of one region by another that makes centralized decision making worse than decentralized decision making. For example, in the absence of behavioral restrictions, regional representatives that can only use public transport in the own region have an incentive to favor imposing high fares in other cities but low fares in their own city. Imposing uniformity of fares across regions prevents such potential exploitation of regions. In addition, in cases where public transport decisions have been taken at the central level, it seems to have been the most commonly observed regime in practice.

Under our assumptions, we show in Appendix 4 that the rule for the fare decided by car owners can be written in the following two equivalent ways (given the symmetry assumption we have deleted the regional index $(i=1,2))$ :

\footnotetext{
${ }^{11}$ They compared the outcome of 4 institutions: decentralized decisions, centralized decision making, centralized decision making under bargaining, and centralized decision making with a uniform pricing constraint across regions. They show that negotiated central decisions and uniform pricing restrictions may outperform decentralization only if non-car owners have a large political majority and there are substantial spill-overs (in the sense that the public transport system is to a large extent used by people from outside the region).

${ }^{12}$ The asymmetric case is discussed in Appendix 4,
} 


$$
\begin{aligned}
& p=c_{Y}+\frac{\beta Y}{f}+\left[1-\left(\frac{\theta^{C}+\theta^{T^{C}}}{1-\eta}\right)\right] v Y \Psi+\left(\tau^{\circ}-\frac{v X}{(1-\eta)}\right) \Psi \\
& p=c_{Y}+\left(\frac{\theta^{C}+\theta^{T^{C}}}{1-\eta}\right) \frac{\beta Y}{f}-\left[1-\left(\frac{\theta^{C}+\theta^{T^{C}}}{1-\eta}\right)\right] \frac{Y}{\frac{\partial Y^{r}}{\partial p}}+\left(\tau^{\circ}-\frac{v X}{(1-\eta)}\right) \Psi
\end{aligned}
$$

In these expressions, the parameter $\theta^{T^{C}}$ captures, in a given region, the share of total regional public transport demand that comes from car owners of the other region (see the discussion in Section 3, especially Table 1):

$$
\theta^{T^{C}}=\frac{Y^{T^{C}}}{Y}=\frac{Y^{T^{C}}}{Y^{U}+Y^{C}+\left(Y^{T^{U}}+Y^{T^{C}}\right)}
$$

Note that this share is likely to be quite small in many regions. It may be substantial in some cases, such as in regions that attract many commuters or tourists.

Turn to the interpretation of (28-29). As car owners were assumed to have the majority in both regions (hence $\eta<0.5 \rightarrow(1-\eta)>0.5$ ), and a regional representative in charge at the central level will take into account that he uses some public transport in both regions, their shares in total public transport demand have the same effect on the fare. What matters is the total share of public transport use by people that own a car, independent of whether they are local or from the other region. The larger this share is, the lower the fare. Similarly, it is the total external cost of car use in the region that matters in the fare, independent of whether it is the local population or the car owners from the other region that suffer from congestion.

More insights can be derived from the comparison of (28) with the rule for the public transport fare we obtained under decentralized decisions. For the case where car owners had a majority, this was given by (24). Direct comparison is not obvious because $\theta^{C}, \theta^{T}, \rho^{C}$ are endogenous: they depend on the policy variables. However, interpretation in a qualitative sense is straightforward.

First, for the sake of the argument, suppose there are no spill-overs at all, in the sense that neither the regional public transport system nor the regional road system is used by outsiders. These assumptions imply (note that $\rho^{T}=0$ implies $\rho^{C}=1$ )

$$
\theta^{T^{C}}=\rho^{T}=0
$$

It follows that under these special conditions centralized and decentralized decisions yield the same fare rule. This directly follows from comparing (24) and (28). This is logical, as all 
public transport demand by car owners comes from within the region (and regions are symmetric) and only local drivers suffer from congestion.

Second, however, suppose that in each region both public transport demand and car use by car owners from outside the region are quite important, so that

$$
\theta^{T^{C}}>0, \quad \rho^{T}>0
$$

The importance of public transport users from outside the region will lead to higher fares under decentralization (see (24)) than under centralized decisions (see (28)). Of course, this is due to tax exporting behavior in the former case. Similarly, let car use by outside users be important in a region, and assume that car transport is under-priced relative to the marginal external cost. Then comparing the final terms on the right hand sides of (24) and (28) implies that decentralized public transport fares will be higher than under centralization. Intuitively, if the region would raise public transport fares it would attract more car traffic, implying higher congestion. The burden of this heavier traffic -- assuming congestion is underpriced -- falls to a substantial extent on outsiders, so the region has an incentive to opt for high public transport fares. In sum, the importance of outside users of both the public transport and the road system imply that decentralized public transport fares are lower than under centralized decisionmaking.

Proposition 4. Comparing centralized and decentralized political decisions (symmetric case with car owner majority)

a. We expect higher fares under decentralized decisions as compared to central decision-making when public transport demand in a region comes to a large extent from outsiders.

b. Similarly, if car use is underpriced compared to its external cost and car use in a region comes to a large extent from outsiders, we expect higher fares for public transport under decentralized decision-making.

c. We expect better cost recovery rates under decentralization.

Note that this proposition yields a prediction that is in principle - given data availability empirically testable. It says that decentralized decision-making will under plausible conditions lead to better cost recovery rates, and that the degree to which decentralized systems cover costs depends on the importance of users of the public transport system that come from outside the region. 


\section{Conclusions}

In this paper we developed a simple model that allows to better understand the political economy of public transport pricing and quality decisions in urban areas. The model considers two types of voters in a region: people that own a car and people that for whatever reason are restricted to public transport use. Assuming the existence of an exogenous road toll (which may be zero) we focus on decisions with respect to the fare, the frequency and the quality of public transport services offered. We then study both decentralized regional decisions under majority voting and compare the expected outcomes with those under centralized decision-making. This paper provides important insights on public transport pricing and investment, assuming given infrastructure and land use.

Under decentralization we find that, if non car owners have the political majority in the region, fares will be below the marginal social cost if there are few outside users of the public transport system and there is no toll on road use. On the contrary, with many outside users and a road toll in place, the fare wanted by the majority may be much higher than the marginal social cost. If car owners have the majority, the resulting fare is increasing in the toll on car use and declining in road congestion; it also decreases if car owners get a larger share of the public transport users surplus. Not surprisingly, cost recovery always improves with the share of users from outside the region.

We further show that imposing a zero deficit restriction on public transport operations implements the second-best welfare optimum, independent of who is in charge at the regional political level. Comparing decentralized outcomes with policy decisions under centralized decision-making, it is found that under plausible conditions higher fares and improved cost recovery rates will result under decentralized decisions.

The model is able to explain at least two observed phenomena. First, it is consistent with the lack of opposition to very large public transport subsidies in Europe. Of course, unsurprisingly, people not owning a car often prefer low public transport fares (and, hence, they favor subsidies), especially if car use is not tolled (because then there are no toll revenues to be redistributed to voters) and few car owners use public transport. However, in many countries very large public transport subsidies get fairly wide political support even when car users have a large majority. The simple intuition is that car users realize that low public transport fares induce some car users to switch to public transport and therefore reduce traffic congestion, from which they suffer. Second, our results may contribute to understanding the observed tendencies towards decentralized public transport decision making. Under plausible 
conditions we found higher fares and better cost recovery rates under decentralized decisions so that, in times of budgetary restrictions and lack of funds, central governments may have an incentive to decentralize decision making on fares and supply decisions in public transport to the regions. This may well be what has happened in many countries in Europe over the past few decades. 


\section{References}

Arnott, R. and R. Grieson (1981), Optimal fiscal policy for a state and local government, Journal of Urban Economics 9, 23-48.

Besley T. and S. Coate S. (2003), Centralized versus decentralized provision of local public goods: a political economy approach, Journal of Public Economics 87, 2611-37.

Blöchliger, H. (2008), Market mechanisms in public service provision, OECD network on foscal relations across governments, working paper $n^{\circ} 6$, OECD.

Borck, R. and M. Wrede (2008), Commuting subsidies with two transport modes, Journal of Urban Economics 63, 841-848.

Brueckner, J.K. and S. Selod (2006), The political economy of urban transport-system choice, Journal of Public Economics 90, 983-1005.

De Borger, B., Dunkerley, F. and S. Proost (2009), Capacity cost structure, welfare and cost recovery: are transport infrastructures with high fixed costs a handicap?, Transportation Research B 43, 506-521.

De Borger, B. and M. Fosgerau (2012), Fares, frequencies and information provision by regulated public transport companies, Transportation Research B 46, 492-510.

De Borger, B. and K. Kerstens (2008), The performance of bus transit operators, in Hensher, D. and K. Button (eds) Handbook of transport modelling, Volume 1, second edition, Elsevier, Amsterdam.

De Borger, B. and S. Proost (2012), A political economy model of road pricing, Journal of Urban Economics, vol. 71 (1), 79-92.

De Borger B. and S. Proost (2013), The political economy of pricing and capacity decisions for congestible local public goods in a federal state, Discussion Paper CES.

De Borger, B. and S. Wouters (1998), Optimal pricing and supply decisions for urban public transport: a simulation analysis for Belgium, Regional Science and Urban Economics 28, 163197.

de Palma, A. and R. Lindsey (2007), Transport user charges and cost recovery, in De Palma, Lindsey and Proost (eds.), Investment and the use of user price and tax revenues in the transport sector, Elsevier, 29-57.

de Palma, A., Kilani, M., Proost, S. (2013). Discomfort in mass transit and its implication for scheduling and pricing. CES - Discussion paper series DPS13.01, 1-19 pp. Leuven (Belgium): KU Leuven CES,. forthcoming in Transportation Research Part B

Frankena, M. (1983), The effect of alternative urban transit subsidy formulas, Journal of Public Economics 15, 337-348.

Gagnepain, P., Ivaldi, M., Martimort D. (2013), The Cost of Contract Renegotiation: Evidence from the Local Public Sector, American Economic Review 103(6), 2352-2383. 
Gagnepain, P., Ivaldi, M. and C. Vibes (2011), The industrial organization of competition in local bus services, in De Palma, Lindsey, Quinet and Vickerman (Eds.), A handbook of transport economics, Edgar Elgar, 744-762.

Glazer, A. and S. Proost (2010), Reducing rent seeking by providing wide public service, CES - Discussion paper series DPS10.31, KULeuven CES.

Glaeser, E.L., Kahn, M.E. and J. Rappaport (2008), Why do the poor live in cities: the role of public transportation, Journal of Urban Economics 63(1), 1-24.

Hickey, R. (2013), Bicameral bargaining and federation formation, Public Choice 154, $217-$ 241.

Holian, M.J. and M.E. Kahn (2013), The Suburbanization of the Median Voter: Implications for Transit and Environmental Policy, Discussion Paper

Jansson, J.O. (1980), A simple bus line model for optimization of service frequency and bus size, Journal of Transport Economics and Policy 14, 53-80.

Jansson, K. (1993), Optimal public transport price and service frequency, Journal of Transport Economics and Policy 27, 33-50.

Jara-Diaz, S.R. and A. Gschwender (2003), Towards a general microeconomic model for the operation of public transport, Transport Reviews 23, 453-469.

Kilani, M., Proost, S. and S. van der Loo (2014, forthcoming), Road pricing and public transport pricing reform in Paris: complements or substitutes?, Economics of Transportation

Kraus, M. (1991), Discomfort externalities and marginal cost transit fares, Journal of Urban Economics 29(2), 249-259.

Lockwood, B. (2002), Distributive politics and the costs of centralization, Review of Economic Studies 69, 313-337.

Mohring, H. (1972), Optimization and scale economies in urban bus transportation, American Economic Review 62, 591-604.

Parry, I.W.H. and K.A. Small (2009), Should urban subsidies be reduced?, American Economic Review 99 (3), 700-724.

Proost, S. and K. Van Dender (2008), Optimal urban transport pricing in the presence of congestion, economies of density and costly public funds. Transportation Research A 42(9), 1220-1230.

Reynolds-Fegan, Durkan and Durkan (2000), Comparison of subvention levels for public transport systems for European cities, Department of Economics, University College Dublin.

Roy, W. and Y. Yvrande-Billon (2007), Ownership, contractual practices and technical efficiency: the case of urban public transport in France, Journal of Transport Economics and Policy. 
Savage, I. (2010), The dynamics of fare and frequency choice, Transportation Research A 44, 815-829.

Tirachini, A., Hensher, D.A. and S.R. Jara-Díaz (2010), Restating modal investment priority with an improved model for public transport analysis, Transportation Research Part E 46, 1148-1168.

Turvey, R. and H. Mohring (1975), Optimal bus fares. Journal of Transport Economics and Policy 9, 280-286.

Van de Velde D.M. (2007), Regulation and competition in the European land transport industry: Recent evolutions, Paper presented at the 9th International Conference on Competition and Ownership in Land Passenger Transport, Lisbon, Portugal.

Vandyck, T., Proost, S. (2012). Inefficiencies in regional commuting policy. Papers in Regional Science, 91(3), 659-689.

Van Goeverden, C., Rietveld, P., Koelemeijer, J. and P. Peeters (2006), Subsidies in public transport, European Transport 32, 5-25.

Wang R., 2011, Autos, transit and bicycles: Comparing the costs in large Chinese cities, Transport Policy 18, 139-146. 


\section{Appendix 1. Derivation of the social optimum (public transport only)}

Consider the problem

$$
\underset{p, f, K}{\operatorname{Max}}\left[\int_{0}^{Y} P^{Y}(y) d y-g^{Y}(.) Y\right]+p Y-f\left(c_{0}+c_{K} K\right)-c_{Y} Y
$$

The first-order condition for the optimal fare can be written as (using equality between generalized price and generalized cost):

$$
-Y \frac{d g^{Y}(.)}{d p}+p \frac{d Y}{d p}+Y-c_{Y} \frac{d Y}{d p}=0
$$

Note by differentiating (2) that

$$
\frac{d g^{Y}(.)}{d p}=1+\frac{\beta}{f} \frac{d Y}{d p}
$$

Substitute this expression in the first-order condition and work out to get

$$
p=c_{Y}+\frac{\beta}{f} Y
$$

Next consider the first-order condition for frequency; again using the equality between generalized price and generalized cost, it can be written as:

$$
-Y \frac{d g^{Y}(.)}{d f}+p \frac{d Y}{d f}-\left(c_{0}+c_{K} K\right)-c_{Y} \frac{d Y}{d f}=0
$$

Differentiating (2) with respect to frequency, we have

$$
\frac{d g^{Y}(.)}{d f}=-\frac{\alpha}{f^{2}}+\beta\left[\frac{f \frac{d Y}{d f}-Y}{f^{2}}\right]=\frac{\beta}{f} \frac{d Y}{d f}-\left(\frac{\alpha+\beta Y}{f^{2}}\right)
$$

Using this expression in the first-order condition and working out we find

$$
\left(p-c_{Y}-\frac{\beta Y}{f}\right) \frac{d Y}{d f}-\left(c_{0}+c_{K} K\right)+\left(\frac{\alpha+\beta Y}{f^{2}}\right) Y=0
$$

The optimal pricing rule (A1.1) allows us to rewrite this expression as

$$
\left(\frac{\alpha+\beta Y}{f^{2}}\right) Y=\left(c_{0}+c_{K} K\right)
$$

Finally, optimal quality investment satisfies the first-order condition

$$
-Y \frac{d g^{Y}(.)}{d K}+p \frac{d Y}{d K}-f c_{K}-c_{Y} \frac{d Y}{d K}=0
$$

We have, by differentiating (2) 


$$
\frac{d g^{Y}(.)}{d K}=\frac{\beta}{f} \frac{d Y}{d K}-\gamma
$$

Using this in the first-order condition and substituting (A1.1) we find

$$
f c_{K}=\gamma Y
$$

\section{Appendix 2: Derivation of the social optimum with un-priced car externalities}

The problem is to

$\underset{p, f, K}{\operatorname{Max}} \int_{0}^{Y} P^{Y}(y) d y+\int_{0}^{X} P^{X}(x) d x-g^{Y}() Y-.g^{X}() X+.\left[p Y-f\left(c_{0}+c_{K} K\right)-c_{Y} Y+\tau^{\circ} X\right]$

The first-order condition for the public transport fare can be written as

$$
-Y\left[\frac{d g^{Y}(.)}{d p}\right]-X\left[\frac{d g^{X}(.)}{d p}\right]+\left[Y+p\left(\frac{d Y}{d p}\right)-c_{Y}\left(\frac{d Y}{d p}\right)+\tau^{\circ} \frac{d X}{d p}\right]=0
$$

Note from (2) and (4) that

$$
\frac{d g^{Y}}{d p}=1+\frac{\beta}{f} \frac{d Y}{d p} ; \quad \frac{d g^{X}}{d p}=v \frac{d X}{d p}
$$

Using these relations in the first-order condition, we obtain

$$
\left(p-c_{Y}-\frac{\beta Y}{f}\right)\left(\frac{d Y}{d p}\right)+\left(\tau^{\circ}-v X\right) \frac{d X}{d p}=0
$$

Substituting the total derivatives as given by (7) in this expression and multiplying by $(\Delta)$, as given in (8), we obtain after simple algebra:

$$
p=c_{Y}+\frac{\beta}{f} Y+\left(\tau^{\circ}-v X\right) \Psi
$$

where

$$
\Psi=-\frac{\frac{d X}{d p}}{\frac{d Y}{d p}}=\frac{\frac{\partial P(Y+X)}{\partial(Y+X)}}{\frac{\partial P(Y+X)}{\partial(Y+X)}-v}>0
$$

Straightforward algebra shows that the second best frequency and quality follow the same rules we derived earlier. To see this, take frequency $f$ as an example. Note by differentiating (2) and (4) that

$$
\frac{d g^{Y}}{d f}=\frac{\beta}{f} \frac{d Y}{d f}-\left(\frac{\alpha+\beta Y}{f^{2}}\right) ; \quad \frac{d g^{X}}{d f}=v \frac{d X}{d f}
$$


It then easily follows that the first-order condition can be written as

$$
\left(p-c_{Y}-\frac{\beta Y}{f}\right)\left(\frac{d Y}{d f}\right)+\left(\tau^{\circ}-v X\right) \frac{d X}{d f}+\frac{\alpha+\beta Y}{f^{2}}-\left(c_{0}+c_{K} K\right)=0
$$

Now observe from (7)-(9) that the Wardrop conditions imply

$$
\frac{d Y}{d f}=-\left(\frac{\alpha+\beta Y}{f^{2}}\right) \frac{d Y}{d p}>0 ; \quad \frac{d X}{d f}=-\left(\frac{\alpha+\beta Y}{f^{2}}\right) \frac{d X}{d p}<0
$$

Substitute these results in (A2.2) and use the optimal fare rule (A2.1) to immediately find

$$
f=\sqrt{\frac{(\alpha+\beta Y) Y}{c_{0}+c_{K} K}}
$$

Following the same steps for $K$ also produces the first-best rule (13). It suffices to take the first-order condition and to note (see (2) and (4))

$$
\frac{d g^{Y}}{d K}=\frac{\beta}{f} \frac{d Y}{d K}-\gamma ; \quad \frac{d g^{X}}{d K}=v \frac{d X}{d K}
$$

Then use (see (7) and (10))

$$
\frac{d Y}{d K}=-\gamma \frac{d Y}{d p}>0 ; \quad \frac{d X}{d K}=-\gamma \frac{d X}{d p}<0
$$

Using these results immediately yields (13).

Finally, impose a no-loss restriction on public transport, and assume that the constraint is binding at the optimum. Denoting the multiplier associated with the constraint by $\lambda$, the first-order condition then reads

$$
\left((1+\lambda)\left(p-c_{Y}\right)-\frac{\beta Y}{f}\right)\left(\frac{d Y}{d p}\right)+\lambda Y+\left(\tau^{\circ}-v X\right) \frac{d X}{d p}=0
$$

The same steps as those described earlier in this appendix (essentially, use (7)-(8)) then easily produces

$$
p=c_{Y}+\frac{\beta}{f} Y+\frac{\lambda}{1+\lambda} Y v \Psi+\frac{1}{1+\lambda}\left(\tau^{\circ}-v X\right) \Psi
$$

\section{Appendix 3: Regional political decisions under budgetary constraints}

First, let voters that only use public transport have a majority; the problem to be studied is then 


$$
\begin{gathered}
\operatorname{Max}_{p, f, K} \frac{1}{U}\left[\int_{0}^{Y^{U}} P^{Y^{U}}(y) d y-g^{Y}(.) Y^{U}\right]+\frac{\left[p Y-f\left(c_{0}+c_{K} K\right)-c_{Y} Y+\tau^{\circ} X\right]}{R} \\
\text { s.t. } \frac{\left[p Y-f\left(c_{0}+c_{K} K\right)-c_{Y} Y\right]}{R}=0
\end{gathered}
$$

Associating a multiplier $\lambda$ with the constraint, we have the first-order condition

$$
-\frac{1}{U} Y^{U} \frac{d g^{Y}}{d p}+\frac{1}{R}\left\{(1+\lambda)\left[\left(p-c_{Y}\right) \frac{d Y}{d p}+Y\right]+\tau^{\circ} \frac{d X}{d p}\right\}=0
$$

Multiply by $R$ and note that we have

$$
\frac{d g^{Y}}{d p}=1+\frac{\beta}{f} \frac{d Y}{d p} ; \quad \eta=\frac{U}{R} ; \quad \theta^{U}=\frac{Y^{U}}{Y}
$$

Using these expressions in the first-order condition gives

$$
\left[p-c_{Y}-\frac{\theta^{U}}{\eta} \frac{1}{1+\lambda} \frac{\beta Y}{f}\right] \frac{d Y}{d p}+\left[1-\frac{\theta^{U}}{\eta} \frac{1}{1+\lambda}\right] Y+\tau^{\circ} \frac{d X}{d p} \frac{1}{1+\lambda}=0
$$

Then, as before, use (7), (8) and (17) to find, after straightforward algebra:

$$
p=\left(c_{Y}+\frac{\beta Y}{f}\right)+\left(1-\frac{\theta^{U}}{\eta} \frac{1}{1+\lambda}\right) v Y \Psi+\tau^{\circ} \frac{1}{1+\lambda} \Psi
$$

A similar procedure yields expression (26) in the text for the case where car owners have the majority.

\section{Appendix 4: Political decisions under centralization}

Throughout we assume car that owners have a majority in both regions. Moreover, we assume that fare and quality policies have to be uniform across regions so as to avoid exploitation of one region by the other (De Borger and Proost (2013)).

To get started, note that we have the following definitions of generalized costs in the regions:

$$
\begin{array}{ll}
g_{1}^{Y}=p+\frac{\alpha_{1}}{f_{1}}+\frac{\beta_{1} Y_{1}}{f_{1}}-\gamma_{1} K_{1} ; & g_{2}^{Y}=p+\frac{\alpha_{2}}{f_{2}}+\frac{\beta_{2} Y_{2}}{f_{2}}-\gamma_{2} K_{2} \\
g_{1}^{X}=\tau_{1}+v_{1} X_{1} ; & g_{2}^{X}=\tau_{2}+v_{2} X_{2}
\end{array}
$$

The car owner from a given region uses four types of transport. For example, the one from region 1 demands public transport and car trips in the own region $\left(Y_{1}^{C}, X_{1}^{C}\right.$, respectively) as well as public transport and car trips in the other region 2 (denoted $Y_{2}^{T^{C}}, X_{2}^{T}$, respectively). 
For details, see Table 1 in the main body of the paper. Further note the following definitions

$$
\begin{aligned}
& \theta_{1}^{U}=\frac{Y_{1}^{U}}{Y_{1}} ; \theta_{1}^{C}=\frac{Y_{1}^{C}}{Y_{1}} ; \theta_{1}^{T^{C}}=\frac{Y_{1}^{T^{C}}}{Y_{1}} ; \theta_{1}^{T^{U}}=\frac{Y_{1}^{T^{U}}}{Y_{1}} \quad \theta_{1}^{U}+\theta_{1}^{C}+\theta_{1}^{T^{C}}+\theta_{1}^{T^{U}}=1 \\
& \theta_{2}^{U}=\frac{Y_{2}^{U}}{Y_{2}} ; \theta_{2}^{C}=\frac{Y_{2}^{C}}{Y_{2}} ; \theta_{2}^{T^{C}}=\frac{Y_{2}^{T^{C}}}{Y_{2}} ; \theta_{2}^{T^{U}}=\frac{Y_{2}^{T^{U}}}{Y_{2}} \quad \theta_{2}^{U}+\theta_{2}^{C}+\theta_{2}^{T^{C}}+\theta_{2}^{T^{U}}=1 \\
& \rho_{1}^{C}=\frac{X_{1}^{U}}{X_{1}} ; \rho_{1}^{T}=\frac{X_{1}^{T}}{X_{1}} \quad \rho_{1}^{C}+\rho_{1}^{T}=1 \\
& \rho_{2}^{C}=\frac{X_{2}^{U}}{X_{2}} ; \rho_{2}^{T}=\frac{X_{2}^{T}}{X_{2}} \quad \rho_{2}^{C}+\rho_{2}^{T}=1
\end{aligned}
$$

We first assume decisions by a Minimum Winning Coalition, then we briefly deal with bargaining. As will become clear below, under symmetry and uniform fares, we have the same rules under both political systems.

\section{Minimum Winning Coalition}

Following, among others, Besley and Coate (2003), this can be modeled by assuming that each region delegates one representative to a federal parliament; at the central level, each representative has an equal probability of being in charge and being decisive.

Suppose the representative from region 1 is decisive (a similar analysis applies when the representative from region 2 is decisive). This can be modeled as the result to the following problem:

$$
\begin{aligned}
& \underset{p, f_{1}, f_{2}, K_{1}, K_{2}}{\operatorname{Max}} \frac{1}{C_{1}}\left\{\left[\int_{0}^{Y_{1}^{C}} P^{Y_{1}^{C}}(y) d y-g_{1}^{Y}(.) Y_{1}^{C}\right]+\left[\int_{0}^{X_{1}^{C}} P^{X_{1}^{C}}(x) d x-g_{1}^{X}(.) X_{1}^{C}\right]\right\} \\
& \frac{1}{C_{1}}\left\{\left[\int_{0}^{Y_{2}^{T}} P^{Y_{2}^{T^{C}}}(y) d y-g_{2}^{Y}(.) Y_{2}^{T^{C}}\right]+\left[\int_{0}^{X_{2}^{T}} P^{X_{2}^{T}}(x) d x-g_{2}^{X}(.) X_{2}^{T}\right]\right\} \\
&+\frac{1}{2 R}\left[\left(p-c_{Y}\right)\left(Y_{1}+Y_{2}\right)+\tau_{1} X_{1}+\tau_{2} X_{2}-f_{1}\left(c_{0}+c_{K} K_{1}\right)-f_{2}\left(c_{0}+c_{K} K_{2}\right)\right]
\end{aligned}
$$

The first two lines capture the net surplus of the car owner from region 1; he derives surplus from car use and public transport use in his own region (line 1) and in the other region (line 2). The representative further takes account of his share in the total net revenues of public transport and tolls on car use in the two regions.

The first order condition with respect to the fare can be written as follows: 


$$
\begin{aligned}
& -\frac{1}{C_{1}}\left\{Y_{1}^{C} \frac{d g_{1}^{Y}(.)}{d p}+X_{1}^{C} \frac{d g_{1}^{X}(.)}{d p}+Y_{2}^{T^{C}} \frac{d g_{2}^{Y}(.)}{d p}+X_{2}^{T} \frac{d g_{2}^{X}(.)}{d p}\right\} \\
& +\frac{1}{2 R}\left\{\left(p-c_{Y}\right) \frac{d\left(Y_{1}+Y_{2}\right)}{d p}+\left(Y_{1}+Y_{2}\right)+\tau_{1} \frac{d X_{1}}{d p}+\tau_{2} \frac{d X_{2}}{d p}\right\}=0
\end{aligned}
$$

Then note the following relations:

$$
\begin{aligned}
& \frac{d g_{1}^{Y}(.)}{d p}=1+\frac{\beta_{1}}{f_{1}} \frac{d Y_{1}}{d p} ; \quad \frac{d g_{2}^{Y}(.)}{d p}=1+\frac{\beta_{2}}{f_{2}} \frac{d Y_{2}}{d p} \\
& \frac{d g_{1}^{X}(.)}{d p}=v_{1} \frac{d X_{1}}{d p} ; \quad \frac{d g_{2}^{X}(.)}{d p}=v_{2} \frac{d X_{2}}{d p}
\end{aligned}
$$

Use these relations in the first order condition, and multiply by $2 R$. Noting that

$$
\frac{U_{1}}{R}=\eta_{1} \rightarrow \frac{R}{R-U_{1}}=\frac{R}{C_{1}}=\frac{1}{1-\eta_{1}}
$$

and using the definitions given above, the first-order condition can be rewritten as

$$
\begin{aligned}
& \frac{d Y_{1}}{d p}\left\{\left(p-c_{Y}\right)-2 \frac{\theta_{1}^{C}}{1-\eta_{1}} \frac{\beta_{1} Y_{1}}{f_{1}}\right\}+\frac{d Y_{2}}{d p}\left\{\left(p-c_{Y}\right)-2 \frac{\theta_{2}^{T^{C}}}{1-\eta_{1}} \frac{\beta_{2} Y_{2}}{f_{2}}\right\} \\
& +\frac{d X_{1}}{d p}\left\{\tau_{1}-2 \frac{\rho_{1}^{C}}{1-\eta_{1}} v_{1} X_{1}\right\}+\frac{d X_{2}}{d p}\left\{\tau_{2}-2 \frac{\rho_{2}^{T}}{1-\eta_{1}} v_{2} X_{2}\right\} \\
& +Y_{1}\left[1-\frac{2 \theta_{1}^{C}}{1-\eta_{1}}\right]+Y_{2}\left[1-\frac{2 \theta_{2}^{T^{C}}}{1-\eta_{1}}\right]=0
\end{aligned}
$$

Substituting the two-region equivalent of (7) in this expression and working out yields the fare as a complicated expression of all parameters and demand components. However, interpretation is not straightforward, and to save space the general result is not reported here. Instead, to ease the interpretation we impose symmetry; in essence, all parameters, the exogenous toll levels etc. are assumed to be the same in both regions. This allows us to reformulate the first-order condition as (since $\rho^{C}+\rho^{T}=1$ ):

$$
\frac{d Y}{d p}\left\{\left(p-c_{Y}\right)-\frac{\beta Y}{f}\left[\frac{\theta^{C}+\theta^{T^{C}}}{1-\eta}\right]\right\}+\frac{d X}{d p}\left\{\tau-v X\left[\frac{1}{1-\eta}\right]\right\}+\left[1-\frac{\left(\theta^{C}+\theta^{T^{C}}\right)}{1-\eta}\right] Y=0
$$

Working out this expression, using (7), and solving for the fare yields the following result:

$$
p=c_{Y}+\frac{\beta Y}{f}+\left[1-\left(\frac{\theta^{C}+\theta^{T^{c}}}{(1-\eta)}\right)\right] v Y \Psi+\left(\tau^{\circ}-\frac{v X}{(1-\eta)}\right) \Psi
$$

This is the expression discussed in the main body of the paper.

A similar method is used to analyze the first order condition with respect to frequency. We imposing symmetry and use the following relations: 


$$
\begin{aligned}
& \frac{d g^{Y}}{d f}=-\frac{\alpha+\beta Y}{f^{2}}+\frac{\beta}{f} \frac{d Y}{d f} \\
& \frac{d g^{X}}{d f}=v \frac{d X}{d f}
\end{aligned}
$$

Using (8) and the optimal rule for the fare just derived, it is easy to show that the first order condition for frequency can be manipulated to yield the first best rule for frequency:

$$
f=\sqrt{\frac{(\alpha+\beta Y) Y}{c_{0}+c_{K} K}}
$$

In a similar fashion we show that quality follows the first best rule.

\section{Bargaining}

Decisions by bargaining can be modeled as the result to the following problem (basically, assuming equal bargaining power this is just the sum of the objective functions of the car owners in the two regions):

$$
\begin{aligned}
\operatorname{Max}_{p, f, K} \frac{1}{C_{1}}\left\{\left[\int_{0}^{Y_{1}^{C}} P^{Y_{1}^{C}}(y) d y-g_{1}^{Y}(.) Y_{1}^{C}\right]+\left[\int_{0}^{X_{1}^{C}} P^{X_{1}^{C}}(x) d x-g_{1}^{X}(.) X_{1}^{C}\right]\right\} \\
\frac{1}{C_{1}}\left\{\left[\int_{0}^{Y_{2}^{T^{C}}} P^{Y_{2}^{T^{C}}}(y) d y-g_{2}^{Y}(.) Y_{2}^{T^{C}}\right]+\left[\int_{0}^{X_{2}^{T}} P^{X_{2}^{T}}(x) d x-g_{2}^{X}(.) X_{2}^{T}\right]\right\} \\
\frac{1}{C_{2}}\left\{\left[\int_{0}^{Y_{2}^{C}} P^{Y_{2}^{C}}(y) d y-g_{2}^{Y}(.) Y_{2}^{C}\right]+\left[\int_{0}^{X_{2}^{C}} P^{X_{2}^{C}}(x) d x-g_{2}^{X}(.) X_{2}^{C}\right]\right\} \\
\frac{1}{C_{2}}\left\{\left[\int_{0}^{Y_{1}^{T^{C}}} P^{Y_{1}^{Y_{1}^{C}}}(y) d y-g_{1}^{Y}(.) Y_{1}^{T^{C}}\right]+\left[\int_{0}^{X_{1}^{T}} P^{X_{1}^{T}}(x) d x-g_{1}^{X}(.) X_{1}^{T}\right]\right\} \\
+2 * \frac{1}{2 R}\left[\left(p-c_{Y}\right)\left(Y_{1}+Y_{2}\right)+\tau_{1} X_{1}+\tau_{2} X_{2}-f_{1}\left(c_{0}+c_{K} K_{1}\right)-f_{2}\left(c_{0}+c_{K} K_{2}\right)\right]
\end{aligned}
$$

The first two lines capture the net surplus of the car owners from region 1; he derives surplus from car use and public transport use in his own region (line 1) and in the other region (line 2). Similarly, the third and fourth lines give the net surplus of the car owner from region two. Bargaining power is assumed to be equal for both regions. Finally, each car owner takes account of his share in the total net revenues of public transport and tolls on car use.

Using analogous methods as before, it easily follows that for symmetric regions we find the same expression for the fare as in the previous case of a minimum winning coalition. 